\title{
1 Microplastic ingestion by zooplankton
}

2 Matthew Cole ${ }^{\mathrm{a}, \mathrm{d},{ }^{*},}$, Pennie Lindeque ${ }^{\mathrm{a}}$, Elaine Fileman ${ }^{\mathrm{a}}$, Claudia Halsband $^{\mathrm{b}}$, Rhys Goodhead ${ }^{\mathrm{c}}$, Julian

3 Moger $^{c}$, Tamara S. Galloway ${ }^{d}$

4 a Plymouth Marine Laboratory, Prospect Place, The Hoe, Plymouth PL1 3DH, UK

5 b Akvaplan-niva AS, FRAM - High North Research Centre for Climate and the Environment, N-9296

6 Troms $\varnothing$, Norway

$7 \quad{ }^{c}$ College of Engineering, Mathematics and Physical Sciences: Physics, Physics Building, University of 8 Exeter, Stocker Road, Exeter EX4 4QL, UK

$9{ }^{\mathrm{d}}$ College of Life and Environmental Sciences: Biosciences, Geoffrey Pope Building, University of Exeter, Stocker Road, Exeter EX4 4QD, UK

* Corresponding author. Tel.: +44 (0)1752 633165; fax: +44 (0)1752 633101. E-mail address: mcol@pml.ac.uk.

\section{Abstract}

Small plastic detritus, termed 'microplastics', are a widespread and ubiquitous contaminant of marine ecosystems across the globe. Ingestion of microplastics by marine biota, including mussels, worms, fish and seabirds, has been widely reported, but despite their vital ecological role in marine food-webs, the impact of microplastics on zooplankton remains under-researched. Here, we show that microplastics are ingested by, and may impact upon, zooplankton. We used bio-imaging techniques to document ingestion, egestion and adherence of microplastics in a range of zooplankton common to the northeast Atlantic, and employed feeding rate studies to determine the impact of plastic detritus on algal ingestion rates in copepods. Using fluorescence and coherent antiStokes Raman scattering (CARS) microscopy we identified that thirteen zooplankton taxa had the 
capacity to ingest $1.7-30.6 \mu \mathrm{m}$ polystyrene beads, with uptake varying by taxa, life-stage and beadsize. Post-ingestion, copepods egested faecal pellets laden with microplastics. We further observed microplastics adhered to the external carapace and appendages of exposed zooplankton. Exposure of the copepod Centropages typicus to natural assemblages of algae with and without microplastics showed that $7.3 \mu \mathrm{m}$ microplastics $\left(>4000 \mathrm{ml}^{-1}\right)$ significantly decreased algal feeding. Our findings imply that marine microplastic debris can negatively impact upon zooplankton function and health.

\section{Keywords}

Plastic debris, microplastics, zooplankton, marine pollution, algal ingestion, coherent anti-Stokes Raman scattering microscopy, CARS

\section{Introduction}

It has been estimated that up to $10 \%$ of plastics produced globally enters our oceans, so it is of little surprise that plastic debris is now a pervasive and resilient pollutant of the marine environment [1,

2]. Larger plastic debris, such as monofilament line, plastic strapping and plastic bags, can entangle, garrotte, drown, or be eaten by an array of marine wildlife [3]. There is compelling evidence that microplastics - small plastic $<5 \mathrm{~mm}$ in diameter - also negatively impact upon marine biota [4]. Microplastics consist of synthetic polymer products manufactured to be of a small size, such as exfoliates in cosmetics [5], and those items derived from the fragmentation of larger plastic debris, for example polyester fibres from fabrics [6], polyethylene fragments from plastic bags [7] and polystyrene particles from buoys and floats [8]. Typically, high-density plastics (e.g. polyvinyl chlorides, polyester) settle out of the water column, whilst low-density plastics (e.g. polyethylene, polystyrene) remain buoyant, although freshwater inputs, storms and biofilm formation may result 
in vertical mixing $[9,10]$. Floating plastic debris is susceptible to local and ocean currents resulting in higher-than-average waterborne microplastic concentrations in areas of confluence [11].

Microplastics are of environmental concern as their small size makes them available to a wide range of marine biota [12]. Microplastic ingestion has been demonstrated in marine organisms, including amphipods, lugworms and barnacles [4], mussels [13], decapod crustaceans [14], seabirds [15], and fish $[16,17]$. Ingested microplastics might obstruct feeding appendages, aggregate and block the alimentary canal, limit the food intake of an organism or be translocated into the circulatory system $[13,14]$. Further, microplastics may introduce toxicants to the organism: firstly, additives incorporated into a plastic during manufacture to improve its properties (e.g., phthalates for malleability and polybrominated diphenyl ethers (PDE) for heat resistance) might leach out of weathered plastic debris $[18,19]$; secondly, the large surface area to volume ratio and hydrophobic properties of microplastics leave them susceptible to the accumulation of hydrophobic organic contaminants (HOCs) which could dissociate post-ingestion [20]. The extent to which microplastics are ingested and can impact upon zooplankton is uncertain. Zooplankton have a vital ecological role in marine ecosystems, both as primary consumers in the marine food web, and in the case of meroplankton, consisting of the juvenile life stage of numerous commercially important species. The widespread presence of small plastic debris in the water column makes interactions between zooplankton and microplastics highly likely; indeed, both small plastic debris and zooplankton $>333 \mu \mathrm{m}$ in diameter have been recurrently sampled together in sea surface trawls and by continuous plankton recorders [4, 11, 21, 22]. Zooplankton display a range of feeding modes, which vary by life-stage, species and prey availability [23]. Zooplankton can use a combination of chemo- and mechano-receptors to select prey, and their ability to preferentially feed on one species of algae over other algae, plastic beads or detritus has been demonstrated [24-26]. Laboratory experiments, in which latex beads were used to model algal ingestion, have shown that zooplankton have the potential to ingest small plastics [26-28]. Uptake of these small plastics likely 
results from indiscriminate feeding modes (e.g. filter-feeding), by which prey with equivalent spherical diameters (ESD) $<100 \mu \mathrm{m}$ are non-selectively fed upon $[23,29]$.

Due to the complexities of sampling and extracting microplastics from the marine environment, existing studies have largely focussed on detritus $>333 \mu \mathrm{m}[1,30]$. However, there is evidence of very small microplastics $(<100 \mu \mathrm{m})$ both in the benthos and water column. Sampling of shoreline, estuarine and harbour sediments has shown the presence of $\sim 20 \mu \mathrm{m}$ diameter fibrous polymers [4, $6,31]$, and microplastic fibres, granules, films and polystyrene spheres ranging in size from $38 \mu \mathrm{m}-1$ $\mathrm{mm}$ [32]. In the water column, sampling with a $80 \mu \mathrm{m}$ mesh in Swedish coastal waters captured 100,000 times greater concentrations of microplastics than when using a $450 \mu \mathrm{m}$ mesh, with a maximal concentration of 102,000 microplastics per $\mathrm{m}^{3}$ sampled near a polyethylene production facility [33]. Sampling of microplastics in this size range is exceptional, as such there is currently insufficient data to determine realistic environmental concentrations of these particles.

Here, we investigate the ingestion of minute microplastics, $\leq 31 \mu \mathrm{m}$ diameter, by a range of zooplankton species, and examine their impact on zooplankton function and feeding. To explore the hypothesis that zooplankton are capable of ingesting microplastics, 15 zooplankton taxa representative of abundant mesozooplankton in northeast Atlantic coastal systems - were exposed to polystyrene spheres in the size range $7.3-30.6 \mu \mathrm{m}$ suspended in natural seawater, then analysed using fluorescence microscopy. Using the copepod Temora longicornis, we explored where $0.4-3.8$ $\mu \mathrm{m}$ microplastics accumulate, both internally and externally, using a novel bio-imaging technique: coherent anti-Stokes Raman scattering (CARS) microscopy. Finally, to test the hypothesis that microplastics negatively impact upon zooplankton feeding, we exposed the copepod Centropages typicus to natural assemblages of algae and polystyrene beads, using fluorometry and flow cytometry to quantify algal ingestion. 


\subsection{Zooplankton sampling}

98

Zooplankton sampling was conducted between November 2011 and October 2012 at Station L4 (50 $15^{\prime} \mathrm{N}, 4^{\circ} 13^{\prime} \mathrm{W}$ ), a coastal site located in the western English Channel $12 \mathrm{~km}$ south of Plymouth, UK $[34,35]$. A $200 \mu \mathrm{m}$ mesh was used to collect zooplankton via horizontal surface tows and vertical hauls. Collected zooplankton were held in $2 \mathrm{~L}$ of seawater within a coolbox, and transported to controlled-temperature facilities at Plymouth Marine Laboratory (Plymouth, UK). For all experimental procedures, we maintained the zooplankton at ambient sea-surface temperatures (ranging $10-17^{\circ} \mathrm{C}$ depending on sampling date). Specimens were hand-selected under a dissecting microscope within two hours of sampling, and then collectively held in $2 \mathrm{~L}$ of filtered seawater $(0.22$ $\mu \mathrm{m}$ Millipore filter) for 24 hours to allow full gut depuration. In all, fourteen mesozooplankton taxa (size: $0.2-20 \mathrm{~mm}$ ), representative of the most commonly occurring zooplankton in the western English Channel and covering a range of life-stages and life-strategies, in addition to cultured Oxyrrhis marina, a heterotrophic dinoflagellate (size: 15-30 $\mu \mathrm{m}$ ), were selected for microplastic ingestion studies (Table 1).

\subsection{Natural seawater preparation}

For the algal ingestion studies, natural seawater $(5 \mathrm{~L})$ was collected from the sea surface at station L4, passed through a $200 \mu \mathrm{m}$ mesh into a polycarbonate carboy and returned to the laboratory within 2 hours. The seawater was further screened with a $100 \mu \mathrm{m}$ mesh to ensure the removal of any grazing micrometazoans then stored in the dark for 24 hours at ambient sea-surface temperature to maintain the natural communities of algae at normal concentrations. Prior to experimental work, the seawater was mixed thoroughly by gentle inversion of the water in the carboy. 


\subsection{Microplastics}

122

Exposures used commercial polystyrene spheres $\left(\right.$ SPHERO $^{\text {TM }}$ Spherotech). With global production rates of 10.6 million tons in 2001 , polystyrene is the fourth most commonly produced polymer in the world and its presence as a constituent of marine debris is commonly reported [30, 36]. The bead sizes used in each experiment $(0.4-30.6 \mu \mathrm{m})$ were selected to be comparable with the prey size range of the zooplankton exposed [23, 37].

\subsection{Microplastic ingestion by zooplankton}

To ascertain whether zooplankton ingest microplastics we conducted exposures using fluorescent polystyrene beads, and used microscopy to assess uptake. Microplastic suspensions were made up by pipetting $20 \mu$ l of 7.3, 20.6 or $30.6 \mu \mathrm{m}$ diameter fluorescently-labelled (yellow fluorescence: 400 $500 \mathrm{~nm}$ excitation, $450-550 \mathrm{~nm}$ emission) polystyrene spheres into glass vials containing $20 \mathrm{ml}$ of filtered seawater $\left(0.1 \% \mathrm{v} / \mathrm{v}: 3,000\right.$ beads $\mathrm{ml}^{-1}(7.3 \mu \mathrm{m}) ; 2,240$ beads $\mathrm{ml}^{-1}(20.6 \mu \mathrm{m}) ; 635$ beads $\mathrm{ml}^{-1}$ $(30.6 \mu \mathrm{m})$ ), then mixed through repeated inversion. With larger zooplankton (e.g. copepods, decapod larvae, chaetognaths), individual specimens were added directly to the vial ( $n=\geq 6$ per exposure), and fitted to a rotating plankton wheel ( $<5$ RPM) for 24-hours. For smaller zooplankton or those with low-survivability in the laboratory (e.g. bivalve larvae, gelatinous holoplankton, 0 . marina), individual specimens were exposed to microplastic suspensions in Petridishes ( $n=\geq 6$ per exposure) at ambient sea temperature for 1 hour (with the exception of bivalve larvae which were exposed for 24 hours using this method). Post-exposure, zooplankton were washed with filtered seawater and transferred to Eppendorf tubes containing $1 \mathrm{ml}$ of $4 \%$ formalin . Ingestion was ascertained by viewing specimens at $\times 40-400$ magnification with an Olympus IMT2 inverted light microscope with fluorescence to determine the presence of polystyrene beads (fluorescing yellow- 
green) within the alimentary canal or body cavity of the zooplankton. To better understand the interactions between zooplankton and microplastics, both live and preserved copepods and select zooplankton specimens were viewed under the microscope for varying lengths of time to observe the feeding process, ingestion, gut passage and egestion of polystyrene beads.

\subsection{Interactions between microplastics and copepods}

To explore the internal distribution and external adherence of microplastics in zooplankton, we firstly exposed the copepod Temora longicornis to polystyrene beads and then employed CARS microscopy (see below) to visualise their uptake. Microplastic suspensions were formulated by adding $12 \mu \mathrm{l}$ of $0.4,1.7$ or $3.8 \mu \mathrm{m}$ diameter non-labelled polystyrene spheres to $24 \mathrm{ml}$ of filtered seawater $\left(0.05 \% \mathrm{v} / \mathrm{v}: 1 \times 10^{6}\right.$ beads $\mathrm{ml}^{-1}(0.4 \mu \mathrm{m}), 380 \times 10^{3}$ beads $\mathrm{ml}^{-1}(1.7 \mu \mathrm{m})$, and $40 \times 10^{3}$ beads per exposure) were added to each vial, rotated at $<5$ RPM at ambient sea temperature for 24 hours. Post-exposure, specimens were poured onto a $200 \mu \mathrm{m}$ mesh suspended in filtered seawater (to prevent damage to the copepods), washed gently, preserved in $4 \%$ formalin and then transferred to the bio-imaging suite at the University of Exeter (Exeter, UK).

\subsection{Coherent anti-Stokes Raman scattering (CARS) microscopy}

CARS microscopy is a novel microscopy technique that provides label-free contrast, based on vibrational spectroscopy [38] which has exceptional capability for locating polymer particles within biological tissues with subcellular precision [39, 40]. CARS imaging was performed using a custombuilt microscopy system based on a commercial confocal laser-scanning microscope and a synchronised dual-wavelength picosecond laser source. Laser excitation was provided by an optical parametric oscillator (OPO) (Levante Emerald, APE, Berlin) pumped with a frequency doubled 

ps, $76 \mathrm{MHz}$ pulse train at $532 \mathrm{~nm}$ with adjustable output power up to $10 \mathrm{~W}$. The OPO produced collinear signal and idler beams with perfect temporal overlap and provided continuous tuning over a range of wavelengths. The signal beam was used as the pump, ranging from 670 to $980 \mathrm{~nm}$ and fundamental of $\mathrm{Nd}$ :Vandium (1064 nm) used as the Stokes beam. The maximum combined output power of the pump and Stokes was approximately $1 \mathrm{~W}$, which was attenuated to reduce the power at the sample to between $15-30 \mathrm{~mW}$. To improve the transmission of the near-IR excitation through the commercial microscope (IX71 and FV300, Olympus UK) the galvanometer mirrors were replaced with silver mirrors and the tube lens was replaced with a MgF2 coated lens. The collinear pump and Stokes beams were directed onto the scanning confocal dichroic which was replaced by a silver mirror with high reflectivity throughout the visible and NIR (21010, Chroma Technologies, USA). The forward-CARS signal was collected by the air condenser, transmitted by the dichroic mirror and directed onto a red-sensitive photomultiplier tube (R3896, Hamamatsu Photonic UK). The epi-CARS signal was collected using the objective lens and separated from the pump and Stokes beams by a long-wave pass dichroic mirror (z850rdc-xr, Chroma Technologies, USA) and directed onto a second R3896 photomultiplier tube at the rear microscope port. The CARS signal was isolated at each photodetector using a single band-pass filters centred at the anti-Stokes wavelengths. Imaging was performed using either a 60X water immersion, or 20X air objective (UPlanS Apo, Olympus UK).

\subsection{Impact of microplastics on copepod feeding}

To determine whether microplastics negatively impact upon a copepod's ability to ingest natural prey, we exposed the copepod Centropages typicus to natural assemblages of algae with and without microplastics, and compared algal ingestion rates between treatments. In our initial experiment, designed to identify the size of microplastic that would have the greatest impact on $C$. typicus feeding, we exposed individual C. typicus specimens ( $n=\geq 6$ per exposure) to $23 \mathrm{ml}$ of natural 

$<5 R P M$ for 24 hours. To quantify algal concentrations within the natural seawater pre- and postexposure, we vacuum filtered the exposure media through a glass fibre filter, and then transferred the filter to $7 \mathrm{ml}$ of acetone, held at $4^{\circ} \mathrm{C}$ in the dark for 24 hours. The chlorophyll levels within the acetone solution were measured using a Turner fluorometer. Since $7.3 \mu \mathrm{m}$ microplastics had the most notable impact on $C$. typicus feeding, we conducted a further experiment to establish a doseresponse relationship between microplastic concentration and food uptake. Microplastic suspensions consisted of $0,2.5,5,10$ or $20 \mu$ ladditions of $7.3 \mu \mathrm{m}$ fluorescent polystyrene beads in $23 \mathrm{ml}$ of natural seawater. A $1.8 \mathrm{ml}$ aliquot of natural seawater was taken from all vials at $\mathrm{T}_{0}$ and fixed with $40 \mu \mathrm{l}$ of $50 \%$ glutaraldehyde (4\% final concentration), inverted for 2 minutes, refrigerated at $4^{\circ} \mathrm{C}$ for 30 minutes and subsequently snap-frozen in liquid nitrogen and stored in a $-80^{\circ} \mathrm{C}$ freezer prior to analysis using analytical flow cytometry. Individual C. typicus ( $n=\geq 6$ per exposure) were added to experimental vials, while controls (with no copepod) were set up to determine natural growth or decline of algae over the exposure period. The vials were incubated on a rotating plankton wheel (5RPM) for 24 hours in the dark. Post-exposure $\left(T_{24}\right)$, a further $1.8 \mathrm{ml}$ aliquot was fixed (as with $T_{0}$ ). Flow cytometric analysis was carried out on thawed natural seawater samples using a BD Accuri C6 flow cytometer [41]. Particle abundance data was subsequently used to calculate the ingestion rates of algae by $C$. typicus [42].

\subsection{Statistical analysis}

Data was analysed using Microsoft Excel. Student's T-tests were used to compare experimental data with controls, with significant difference attributed where $P \leq 0.05$. Regression analysis was used to analyse the correlation between algal ingestion rates and microplastic concentration. 


\subsection{Microplastic ingestion by zooplankton}

219 The majority of zooplankton (13 of 15$)$ exposed to polystyrene beads $(7.3-30.6 \mu \mathrm{m})$ demonstrated the capacity to ingest microplastics (Table 1). Organisms exhibiting uptake included copepods (Fig. 1i + Fig. 1ii), bivalve larvae (Fig. 1iii) and decapod larvae (Fig. 1iv + Fig. 1v). Only two specimens chaetognaths (Parasagitta sp.) and siphonophorae (Cnidaria) - showed no evidence of ingestion. All four species of copepods examined demonstrated some affinity for ingesting microplastics, with Centropages typicus and Temora longicornis able to consume 7.3, 20.6 and $30.6 \mu \mathrm{m}$ polystyrene beads (Fig. 1ix). The other copepods showed evidence of size-based selectivity: Acartia clausi ingested $7.3 \mu \mathrm{m}$ beads but ingested significantly less 20.6 and $30.6 \mu \mathrm{m}$ beads, and Calanus helgolandicus showed significantly less affinity for $30.6 \mu \mathrm{m}$ beads than for $7.3 \mu \mathrm{m}$ beads. The decapod Brachyurans demonstrated variability in microplastic ingestion depending upon life-stage: brachyuran zoea showed no affinity for $20.6 \mu \mathrm{m}$ beads, while the more-developed brachyuran megalopa readily ingested such beads. Obelia sp., Paguridae larvae and Porcellinidae (zoea) exhibited individual variability in their ability to ingest polystyrene beads, with less than half the exposed specimens in a cohort showing evidence of microplastic uptake.

Live observations of copepods, euphausids and doliolids found microplastics were ingested via filterfeeding. In copepods and euphausids, this process relied upon the rapid movement of the swimming legs and external appendages, which generated a feeding current that indiscriminately drew surrounding beads towards the organism. With doliolids, we observed the microplastics being drawn through the anterior siphon into their body cavity, where the polystyrene beads were entrapped and drawn towards the gut. Oxyrrhis marina, a single celled heterotrophic dinoflagellate, demonstrated a more direct method of ingestion, locating particles with their flagella and then engulfing the polystyrene beads. Post- ingestion, copepods typically aggregated beads within the anterior mid-gut, shifted them to the posterior mid-gut via peristaltic action (Fig. 1i + Fig. 1ii) and egested them within 
densely-packed faecal pellets (Fig. 1vi + Fig. 1viii). Typically, microplastic-laden faecal pellets were egested within hours. In the absence of food, individual microplastic beads could remain in the intestinal tract of $C$. helgolandicus for up to 7 days (data not shown). During observations of both live and preserved zooplankton specimens, including copepods, decapod larvae and euphausids, microplastics often adhered to the specimens' external surfaces. In copepods that died during the exposure period, polystyrene beads would coat the carapace in vast numbers; similarly, beads were observed to cling to the shed carapace of a moulting $C$. helgolandicus copepodite. In live specimens, microplastics were found to concentrate between the external appendages of copepods, including the swimming legs, feeding apparatus, antennae and furca (Fig. 1vii).

\subsection{Interactions between microplastics and copepods}

CARS microscopy used a blend of transmitted light to capture the structure of the copepod, and Raman shifts of $2845 \mathrm{~cm}^{-1}$ (C-H) and $3050 \mathrm{~cm}^{-1}$ (aromatic C-H) to visualise the polystyrene (Fig. 2i). Temora longicornis ingested both 1.7 and $3.8 \mu \mathrm{m}$ polystyrene beads; use of Z-stacking - in which 2D images at incremental focal plains are layered together to form a 3D image - confirmed that microplastics clumping in the posterior mid-gut were, indeed, internalised (Fig. 2ii; yellow dots), but sufficient resolution to identify microplastic translocation was not possible. CARS imaging confirmed that microplastics adhere to the external appendages of the zooplankton: polystyrene beads $(0.4-$ 3.8 $\mu \mathrm{m}$ ) accumulated between the filamental hairs on appendages, including the furca (Fig. 2iii; blue dots), rear swimming legs (Fig. 2iii; red dots) and antennules, and between the segments of the carapace, particularly around the urosome and swimming legs. 
Using chlorophyll concentration as a proxy for algal abundance, we identified that $7.3 \mu \mathrm{m}$ microplastics had a significant impact on algal ingestion by the copepod Centropages typicus (data not shown) and identified a significant dose-response relationship between ingestion rates and the concentration of $7.3 \mu \mathrm{m}$ polystyrene beads. Exposed to seawater - containing natural assemblages of algae - C. typicus ingested $\sim 12$ Synechococcus sp. ind ${ }^{-1} h^{-1}$ (Fig. 3i) and $\sim 24$ picoeukaryotes ind ${ }^{-1} h^{-1}$ (Fig. 3ii). These ingestion rates decreased when additionally exposed to $\sim 4,000$ microplastics $\mathrm{ml}^{-1}$; this decrease was statistically significant at concentrations of $\geq 7,000$ microplastics $\mathrm{ml}^{-1}$ (t-test: $P$ $\leq 0.05)$. When considering all of the $<20 \mu \mathrm{m}$ ESD algal groups identified using flow cytometry Synechococcus sp., picoeukaryotes, nanoeukaryotes and cryptophytes - in combination (hereafter referred to as "total algae"), C. typicus presented total algal ingestion rates of $\sim 34$ algae ind ${ }^{-1} \mathrm{~h}^{-1}$ in the absence of microplastics. Total algal ingestion rates for $C$. typicus were significantly reduced with the addition of $\geq 4,000$ microplastics $\mathrm{ml}^{-1}$ (t-test: $P \leq 0.05$; Fig. 3iii). Furthermore, we identified a strong, logarithmic relationship $\left(R^{2}=0.70, P \leq 0.05\right)$ between the ingestion rate of total algae and microplastic concentration (Fig. 3iv).

\section{Discussion}

Our results show that a range of zooplankton common to the northeast Atlantic can ingest microplastics (1.4 - $30.6 \mu \mathrm{m}$ diameter), with capacity for uptake varying between species, life-stage and microplastic size. Microplastics were indiscriminately ingested via filter-feeding and later egested in faecal pellets, typically within a matter of hours. Microplastics accumulated on the external surface of dead zooplankton, and were found trapped between the external appendages of live copepods. We visualised 1.7 and $3.8 \mu \mathrm{m}$ polystyrene beads clustered within the alimentary canal and aggregated between the setae and joints of external appendages. Lastly, we demonstrated that the presence of $7.3 \mu \mathrm{m}$ polystyrene beads could significantly reduce the algal ingestion rate of the copepod Centropages typicus, in a dose-response relationship. 
We demonstrated that thirteen zooplankton taxa - including holoplankton, meroplankton and microzooplankton - have the capacity to ingest polystyrene beads in the absence of natural food. All four copepod species showed uptake of microplastics, with varying degrees of selectivity: $T$. longicornis and C. typicus ingested 7.3, 20.6 and $30.6 \mu \mathrm{m}$ beads, while $A$. clausi and $C$. helgolandicus fed on $7.3 \mu \mathrm{m}$ beads but less frequently ingested larger beads. Using CARS microscopy, we further identified that $T$. longicornis could ingest 1.7 and $3.8 \mu \mathrm{m}$ microplastics, however, we found no evidence of $0.4 \mu \mathrm{m}$ beads being ingested. Brachyuran larvae only ingested $20.6 \mu \mathrm{m}$ polystyrene beads as megalopa (post-zoea larvae), with no uptake observed when in the earlier zoea stage. Microplastics were also ingested by the filter-feeding euphausids and doliolids, and Oxyrrhis marina, a heterotrophic dinoflagellete that ingests motile or immotile prey through engulfment via a nonpermanent cytosome [43]. These findings corroborate the results of several previous studies, which documented the uptake of $<100 \mu \mathrm{m}$ microplastics by Acartia tonsa [28], Calanus pacificus adults, copepodites and nauplii [26, 44, 45], Oxyrrhis marina [46], ciliates [47, 48], echinoderm larvae [27] and salps [49].

We did not observe microplastic uptake in Parasagitta sp. (chaetognaths) following 1- or 24- hour exposures to $30.6 \mu \mathrm{m}$ beads, or siphonophorae (Cnidaria) exposed to $20.6 \mu \mathrm{m}$ plastics, possibly as a result of handling stress, or more likely because these zooplankton are raptorial predators and feed actively, so were not enticed to capture the immotile microplastics [37]. Furthermore, only $10-50 \%$ of Obelia sp., Paguridae larvae and Porcellinidae (zoea) specimens presented with polystyrene beads in their intestinal tracts post-exposure. As we also observed size-selective ingestion in A. clausi and C. helgolandicus, it is important to consider how microplastics may impact on different zooplankton feeding strategies. Zooplankton use both mechanoreception (i.e. detection of pressure disturbances within the water) and chemoreception (i.e. detection of infochemicals emitted by algal cells) to sense prey $[29,37]$. As such, the clean immotile beads used in our algal-free experiments are less likely to be detected by exposed zooplankton, although it is possible that aged microplastics, that have developed bio-films during their residence within the marine environment [10], may generate a 
chemosensory response; this effect was observed in the copepod Eurytemora affinis which more readily ingested beads spiked with bacteria than when offered beads alone [50]. While some copepods will continuously filter-feed regardless of prey availability, others (e.g. C. pacificus, A. tonsa) can limit their movement and filter-feed at reduced rates to conserve energy when faced with low food-concentrations $[51,52]$. The presence of algae promotes greater uptake of microplastics in the filter-feeding copepods Calanus pacificus [26] and Eucalanus pileatus CV copepodites [53]; notably, A. clausi only ingests $16 \mu \mathrm{m}$ polystyrene beads in the presence of algae [24]. Some zooplankton can ingest or reject prey upon capture, depending on surface characteristics and charge of the particle, both echinoderm larvae and the copepods A. clausi and E. pileatus can reject plastic beads that coalesced within their mouthparts $[27,53,54]$. The presence of microplastics may also alter the behaviour of zooplankton, limiting their capacity to feed: in Acartia tonsa copepodites, contact with $45 \mu \mathrm{m}$ plastic beads caused the organisms to "jump", limiting time dedicated to feeding bouts and reducing their clearance rates by $60 \%$ [55].

Post-ingestion, polystyrene beads were observed to coalesce within the mid-gut of copepods prior to egestion. While gut-retention times of these microplastics were typically similar to natural food items (i.e. egestion occurred within hours), a follow-up experiment found some Calanus helgolandicus individuals retained microplastics for up to 7 days. Microplastics found in the marine environment include fibres, granules and fragments manufactured from a range of polymers [30]; if such irregularly-shaped and fibrous microplastics were ingested, they may become entangled within the intestinal tract, potentially resulting in a non-biodegradable gut-blockage and greater gutretention times. Plastic fibres entangle within the intestinal tracts of Nephrops in this manner [14], while fish $[16,17]$ and seabird dissections [15] have demonstrated that marine wildlife can retain a range of plastic detritus within their stomachs near-indefinitely. Prolonged gut-retention times of plastics and gut-blockages in zooplankton may limit the ability of these organisms to ingest and digest food, and may pose a toxic risk. During manufacture, a suite of additives (e.g. plasticisers, flame-retardants, anti-microbials) are added to plastics, and large surface area to volume ratio and 
hydrophobic properties of microplastics make them particularly susceptible to the adherence of waterborne contaminants (e.g. PCBs, DDT and PAHs) [19]. The leaching of additives and disassociation of toxic contaminants post-ingestion has been modelled in polychaete worms [56] and demonstrated in streaked shearwaters [57]. In zooplankton, as with other marine biota, these contaminants might be considered endocrine-disruptors, carcinogenic or toxic, with repercussions for growth, sexual development, fecundity, morbidity and mortality $[58,59]$. Of further concern is trophic-transfer: microplastics (and contaminants released from microplastics) within lower-trophic, keystone organisms such as zooplankton may result in the trophic-transfer of these contaminants up the food-chain, with the potential for bio-accumulation and therefore adverse health consequences in higher trophic organisms.

Copepods that died during exposures, and shed moults of copepodites, were coated in microplastics - presumably because of hydrophobic- or static-attractions between the negatively-charged polystyrene (average zeta potential: $-41.8 \mathrm{mV}$ ) and organic material - a process that acts to concentrate microplastics from the surrounding seawater. Our observations of microplastic laden faecal pellets egested by copepods provided no indication that passage through the alimentary canal had any discernible impact on the microplastics. However, plastics may alter the density and structural integrity of faecal pellets with potential repercussions on vertical carbon flux [60]. During our studies, we also found microplastics were becoming trapped between the external appendages and carapace segments of live copepods. We found that very small microplastics $(0.4-3.8 \mu \mathrm{m})$ became lodged between the filamental hairs and setae of the antennules, furca and the swimming legs $[29,61]$. As these appendages have key roles in copepod function and behaviour, this may have repercussions for locomotion, ingestion, mating and mechanoreception, that may limit their ability to detect prey, feed, reproduce and evade predators.

We found that the presence of $7.3 \mu \mathrm{m}$ beads significantly reduced the amount of algae eaten by the copepod Centropages typicus, whereas $20.6 \mu \mathrm{m}$ beads showed no discernible impact on algal 
consumption. This suggests $C$. typicus can preferentially feed upon algae over $20.6 \mu \mathrm{m}$ beads (but could not differentiate between the algae and $7.3 \mu \mathrm{m}$ beads), or, that only the smaller beads impact on copepod feeding (i.e. 7.3 $\mu \mathrm{m}$ beads are small enough to become entrapped between external appendages or be recurrently ingested). A similar finding has been observed with Acartia clausi and Calanus pacificus nauplii, which selectively fed upon small algae while avoiding larger beads, but could not discriminate between algae and beads of a similar size $[24,45,54]$. We found that a concentration of 4,000 beads $\mathrm{ml}^{-1}$ was enough to result in significantly reduced algal ingestion rates. This relationship reached saturation at concentrations of $>5000$ beads $\mathrm{ml}^{-1}$. Two previous studies have found similar results, where the ingestion rates of the copepod A. clausi [24] and C. pacificus [45] were significantly reduced by the presence of beads of a similar size to the algae. A reduction in algal feeding may have severe consequences for copepods, as limited energy intake, in particular with species that have minimal lipid reserves (e.g. Centropages, Acartia), could result in decreased fecundity and growth, or increased mortality [24,62]. We do not yet know whether 5000 particles $\mathrm{ml}^{-1}$ can be considered an environmentally relevant concentration for microplastics $<10 \mu \mathrm{m}$ in size. Perpetual fragmentation of plastic litter, coupled with the increasing popularity of household products containing microscopic plastic exfoliates [5], suggests marine plastic debris is becoming, on average, smaller over time [63]. However, due to the complexities of sampling and extraction, and in the absence of unified sampling methodologies, microplastics are still considered to be an underresearched fraction of marine litter, with no consistent data relating to plastic detritus $<333 \mu \mathrm{m}$ in diameter $[1,30,64]$. Further, we must consider that microplastics made of polymers other than polystyrene, potentially laden with chemical additives or adhered contaminants, could result in different interactions with zooplankton with variable impacts on function.

Our findings confirm that ingestion of marine microplastic debris by zooplankton in the ocean is feasible. Potential impacts include reduced function and health of the individual, trophic-transfer of contaminants to predators, and the egestion of faecal pellets containing microplastics. Better 

imperative.

394

\section{Acknowledgments}

Matthew Cole is supported by a NERC PhD studentship (Grant 1528034). We thank the crews of the

Plymouth Quest and MBA Sepia for the collection of zooplankton and seawater, Rachel Harmer and

Andrea McEvoy for zooplankton identification and Glen Tarran for assistance with flow cytometry work.

400

\section{Figure Legends}

402

Figure 1: Microplastics of different sizes can be ingested, egested and adhere to a range of zooplankton, as visualised using fluorescence microscopy: (i) the copepod Centropages typicus containing $7.3 \mu \mathrm{m}$ polystyrene (PS) beads (dorsal view); (ii) the copepod Calanus helgolandicus containing $20.6 \mu \mathrm{m}$ PS beads (lateral view); (iii) a D-stage bivalve larvae containing $7.3 \mu \mathrm{m}$ PS beads (dorsal view); (iv) a Brachyuran (decapod) larvae (zoea stage) containing $20.6 \mu \mathrm{m}$ PS beads (lateral view); (v) a Porcellanid (decapod) larvae, containing $30.6 \mu \mathrm{m}$ PS beads (lateral view); (vi) $30.6 \mu \mathrm{m}$ PS beads in the posterior-gut of the copepod Temora longicornis during egestion, (vii) $1.4 \mu \mathrm{m}$ PS beads trapped between the filamental hairs of the furca of $C$. typicus; (viii) a $T$. longicornis faecal pellet containing $30.6 \mu \mathrm{m}$ PS beads; (ix) proportion of copepods (Acartia clausi, Calanus helgolandicus, exposure to $7.4,20.6$ and $30.6 \mu \mathrm{m}$ polystyrene beads. * denotes statistically significant $(P \leq 0.05)$

413 lower consumption of larger beads compared with that of $7.3 \mu \mathrm{m}$ beads. Scale bar (grey line): 100 $\mu \mathrm{m}$. 
416 Figure 2: Coherent anti-Stokes Raman scattering (CARS) microscopy: (i) Spontaneous [•] and 417 stimulated [ [ ] peaks for polystyrene beads, Raman shifts of $2845 \mathrm{~cm}^{-1}$ (C-H) and $3050 \mathrm{~cm}^{-1}$ (aromatic $418 \mathrm{C}-\mathrm{H}$ ) were used to visualise the polystyrene; (ii) $3.4 \mu \mathrm{m}$ microplastics accumulated in the alimentary 419 canal [ac] of the copepod Temora longicornis (yellow dots); beads further adhered to the exterior of 420 the copepod's urosome [u], furca [f] and posterior swimming legs [sl] (blue dots); (ii) $3.4 \mu \mathrm{m}$ 421 microplastics (red dots) adhered to the external surface of the posterior swimming legs of $T$. 422 longicornis. Scale bar [grey line]: $50 \mu \mathrm{m}$.

423

424 Figure 3: Exposure to increasing concentrations of microplastics in the copepod Centropages typicus $425(n=\geq 5)$. Treatments comprise seawater containing natural assemblages of algae $[A]$ with 4,000 [B], $4267,000[\mathrm{C}], 11,000[\mathrm{D}]$ and 25,000 [E] $7.3 \mu \mathrm{m}$ polystyrene beads per ml. * denotes statistically 427 significant $(P \leq 0.05)$ lower ingestion rates (cells individual ${ }^{-1}$ hour $^{-1}$ ) than in controls. Graphs show 428 ingestion rates of: (i) Synechococcus sp.; (ii) Picoeukaroytes; (iii) all algae present; (iv) plot comparing 429 positive C. typicus algal ingestion rates at differing microplastics concentrations - logarithmic 430 regression: $\mathrm{R}^{2}=0.70(P \leq 0.05)$. 
Table 1: The capacity for a range of zooplankton to ingest microplastics, demonstrated using fluorescent microscopy.

\begin{tabular}{|c|c|c|c|c|}
\hline Organism & Taxonomy & Microplastic & Exposure & Ingestion \\
\hline \multicolumn{5}{|l|}{ Holoplankton (Copepods) } \\
\hline Acartia clausi & Copepoda (Calanoida) & 7.3 & 24 & Yes \\
\hline Acartia clausi & Copepoda (Calanoida) & 20.6 & 24 & No \\
\hline Acartia clausi & Copepoda (Calanoida) & 30.6 & 24 & Partial \\
\hline Calanus helgolandicus & Copepoda (Calanoida) & 7.3 & 24 & Yes \\
\hline Calanus helgolandicus & Copepoda (Calanoida) & 20.6 & 24 & Yes \\
\hline Calanus helgolandicus (juv.) & Copepoda (Calanoida) & 20.6 & 24 & Yes \\
\hline Calanus helgolandicus & Copepoda (Calanoida) & 30.6 & 24 & Partial \\
\hline Centropages typicus & Copepoda (Calanoida) & 7.3 & 24 & Yes \\
\hline Centropages typicus & Copepoda (Calanoida) & 20.6 & 24 & Yes \\
\hline Centropages typicus & Copepoda (Calanoida) & 30.6 & 24 & Yes \\
\hline Temora longicornis & Copepoda (Calanoida) & 7.3 & 24 & Yes \\
\hline Temora longicornis & Copepoda (Calanoida) & 20.6 & 24 & Yes \\
\hline Temora longicornis & Copepoda (Calanoida) & 30.6 & 24 & Yes \\
\hline \multicolumn{5}{|l|}{ Holoplankton (Other) } \\
\hline Doliolidae & Tunicata & 7.3 & 1 & Yes \\
\hline Euphausiidae & Euphausiacea & 20.6 & 24 & Yes \\
\hline Parasagitta sp. & Chaetognatha & 20.6 & 1 & No \\
\hline Parasagitta sp. & Chaetognatha & 30.6 & 24 & No \\
\hline Obelia sp. & Cnidaria (Hydrozoa) & 20.6 & 1 & Partial \\
\hline Siphonophorae & Cnidaria (Hydrozoa) & 20.6 & 1 & No \\
\hline \multicolumn{5}{|l|}{ Meroplankton } \\
\hline Bivalvia (larvae) & Mollusca & 7.3 & 24 & Yes \\
\hline Brachyura (megalopa) & Decapoda & 20.6 & 24 & Yes \\
\hline Brachyura (zoea) & Decapoda & 20.6 & 24 & No \\
\hline Caridea (larvae) & Decapoda & 20.6 & 24 & Yes \\
\hline Paguridae (larvae) & Decapoda & 20.6 & 24 & Partial \\
\hline Porcellanidae (zoea) & Decapoda & 30.6 & 24 & Partial \\
\hline \multicolumn{5}{|l|}{ Microzooplankton } \\
\hline Oxyrrhis marina & Dinoflagellata & 7.3 & 1 & Yes \\
\hline
\end{tabular}

Microplastic uptake is based upon the number of individuals in a treatment $(n=\geq 6)$ that contained beads in their alimentary canals or body cavity following 1 or 24 hour exposures to either $7.3,20.6$ or $30.6 \mu \mathrm{m}$ fluorescent polystyrene beads. ESD = Equivalent Spherical Diameter. Scoring system: Yes (>50\%); Partial $(<50 \%)$; No $(0 \%)$. 
1. Cole, M.; Lindeque, P.; Halsband, C.; Galloway, T. S., Microplastics as contaminants in the marine environment: A review. Marine Pollution Bulletin 2011, 62, 2588-2597.

2. Thompson, R. C., Plastic debris in the marine environment: consequences and solutions. Marine Nature Conservation in Europe 2006, 193, 107-115.

3. Derraik, J. G. B., The pollution of the marine environment by plastic debris: a review. Marine Pollution Bulletin 2002, 44, (9), 842-852.

4. Thompson, R. C.; Olsen, Y.; Mitchell, R. P.; Davis, A.; Rowland, S. J.; John, A. W. G.; McGonigle, D.; Russell, A. E., Lost at Sea: Where Is All the Plastic? Science 2004, 304, (5672), 838.

5. Fendall, L. S.; Sewell, M. A., Contributing to marine pollution by washing your face: Microplastics in facial cleansers. Marine Pollution Bulletin 2009, 58, (8), 1225-1228.

6. Browne, M. A.; Crump, P.; Niven, S. J.; Teuten, E.; Tonkin, A.; Galloway, T.; Thompson, R., Accumulation of microplastics on shorelines worldwide: Sources and sinks. Environmental Science \& Technology 2011, 45, (21), 9175-9179.

7. O'Brine, T.; Thompson, R. C., Degradation of plastic carrier bags in the marine environment. Marine Pollution Bulletin 2010, 60, (12), 2279-2283.

8. Davidson, T. M., Boring crustaceans damage polystyrene floats under docks polluting marine waters with microplastic. Marine Pollution Bulletin 2012, 64, (9), 1821-1828.

9. Lattin, G. L.; Moore, C. J.; Zellers, A. F.; Moore, S. L.; Weisberg, S. B., A comparison of neustonic plastic and zooplankton at different depths near the southern California shore. Marine Pollution Bulletin 2004, 49, (4), 291-294.

10. Lobelle, D.; Cunliffe, M., Early microbial biofilm formation on marine plastic debris. Marine Pollution Bulletin 2011, 62, (1), 197-200.

11. Collignon, A.; Hecq, J.-H.; Galgani, F.; Voisin, P.; Collard, F.; Goffart, A., Neustonic microplastic and zooplankton in the North Western Mediterranean Sea. Marine Pollution Bulletin 2012, 64, (4), 861-864.

12. Barnes, D. K. A.; Galgani, F.; Thompson, R. C.; Barlaz, M., Accumulation and fragmentation of plastic debris in global environments. Philosophical Transactions of the Royal Society B: Biological Sciences 2009, 364, (1526), 1985-1998.

13. Browne, M. A.; Dissanayake, A.; Galloway, T. S.; Lowe, D. M.; Thompson, R. C., Ingested Microscopic Plastic Translocates to the Circulatory System of the Mussel, Mytilus edulis (L.). Environmental Science \& Technology 2008, 42, (13), 5026-5031.

14. Murray, F.; Cowie, P. R., Plastic contamination in the decapod crustacean Nephrops norvegicus (Linnaeus, 1758). Marine Pollution Bulletin 2011, 62, (6), 1207-1217.

15. van Franeker, J. A.; Blaize, C.; Danielsen, J.; Fairclough, K.; Gollan, J.; Guse, N.; Hansen, P.-L.; Heubeck, M.; Jensen, J.-K.; Le Guillou, G.; Olsen, B.; Olsen, K.-O.; Pedersen, J.; Stienen, E. W. M.; Turner, D. M., Monitoring plastic ingestion by the northern fulmar Fulmarus glacialis in the North Sea. Environmental Pollution 2011, 159, (10), 2609-2615.

16. Boerger, C. M.; Lattin, G. L.; Moore, S. L.; Moore, C. J., Plastic ingestion by planktivorous fishes in the North Pacific Central Gyre. Marine Pollution Bulletin 2010, 60, (12), 2275-2278.

17. Davison, P.; Asch, R. G., Plastic ingestion by mesopelagic fishes in the North Pacific Subtropical Gyre. Marine Ecology Progress Series 2011, 432, 173-180.

18. Talsness, C. E.; Andrade, A. J. M.; Kuriyama, S. N.; Taylor, J. A.; vom Saal, F. S., Components of plastic: experimental studies in animals and relevance for human health. Philosophical Transactions of the Royal Society B: Biological Sciences 2009, 364, (1526), 2079-2096.

19. Teuten, E. L.; Saquing, J. M.; Knappe, D. R. U.; Barlaz, M. A.; Jonsson, S.; BjÃrn, A.; Rowland, S. J.; Thompson, R. C.; Galloway, T. S.; Yamashita, R.; Ochi, D.; Watanuki, Y.; Moore, C.; Viet, P. H.; Tana, T. S.; Prudente, M.; Boonyatumanond, R.; Zakaria, M. P.; Akkhavong, K.; Ogata, Y.; Hirai, H.; Iwasa, S.; Mizukawa, K.; Hagino, Y.; Imamura, A.; Saha, M.; Takada, H., Transport and release of 
chemicals from plastics to the environment and to wildlife. Philosophical Transactions of the Royal Society B: Biological Sciences 2009, 364, (1526), 2027-2045.

20. Mato, Y.; Isobe, T.; Takada, H.; Kanehiro, H.; Ohtake, C.; Kaminuma, T., Plastic Resin Pellets as a Transport Medium for Toxic Chemicals in the Marine Environment. Environmental Science \& Technology 2001, 35, (2), 318-324. Moore, C. J. Moore, S. L. Leecaster, M. K. Weisberg S. B., A Comparison of Plastic and Plankton in the North Pacific Central Gyre. Marine Pollution Bulletin 2001, 42, (12), 1297-1300.

22. Moore, C. J.; Moore, S. L.; Weisberg, S. B.; Lattin, G. L.; Zellers, A. F., A comparison of neustonic plastic and zooplankton abundance in southern California's coastal waters. Marine Pollution Bulletin 2002, 44, (10), 1035-1038.

23. Wirtz, K. W., Who is eating whom? Morphology and feeding type determine the size relation between planktonic predators and their ideal prey. In 2012; Vol. 445, pp 1-12.

24. Ayukai, T., Discriminate feeding of the calanoid copepod Acartia clausi in mixtures of phytoplankton and inert particles. Marine Biology 1987, 94, (4), 579-587.

25. DeMott, W. R., Discrimination Between Algae and Detritus by Freshwater and Marine Zooplankton. Bulletin of Marine Science 1988, 43, (3), 486-499.

26. Frost, B. W., Feeding Behavior of Calanus pacificus in Mixtures of Food Particles. Limnology and Oceanography 1977, 22, (3), 472-491.

27. Hart, M. W., Particle Captures and the Method of Suspension Feeding by Echinoderm Larvae. The Biological Bulletin 1991, 180, (1), 12-27.

28. Wilson, D. S., Food Size Selection Among Copepods. Ecology 1973, 54, (4), 909-914.

29. Mauchline, J., The Biology of Calanoid Copepods. Academic Press: London, 1998.

30. Hidalgo-Ruz, V.; Gutow, L.; Thompson, R. C.; Thiel, M., Microplastics in the marine environment: A review of the methods used for identification and quantification. Environmental Science \& Technology 2012, 46, (6), 3060-3075.

31. Browne, M. A.; Galloway, T. S.; Thompson, R. C., Spatial Patterns of Plastic Debris along Estuarine Shorelines. Environmental Science \& Technology 2010, 44, (9), 3404-3409.

32. Claessens, M.; Meester, S. D.; Landuyt, L. V.; Clerck, K. D.; Janssen, C. R., Occurrence and distribution of microplastics in marine sediments along the Belgian coast. Marine Pollution Bulletin 2011, 62, (10), 2199-2204.

33. Lozano, R. L.; Mouat, J. Marine litter in the North-East Atlantic Region: Assessment and priorities for response.; KIMO International: 2009.

34. Harris, R., The L4 time-series: the first 20 years. Journal of Plankton Research 2010, 32, (5), 577-583.

35. Smyth, T. J.; Fishwick, J. R.; Al-Moosawi, L.; Cummings, D. G.; Harris, C.; Kitidis, V.; Rees, A.; Martinez-Vicente, V.; Woodward, E. M. S., A broad spatio-temporal view of the Western English Channel observatory. Journal of Plankton Research 2010, 32, (5), 585-601.

36. PlasticsEurope Plastics - the facts 2010. http://www.plasticseurope.org/documents/document/20101028135906final plasticsthefacts $26102010 \mathrm{Ir}$.pdf

37. Kiørboe, T., How zooplankton feed: mechanisms, traits and trade-offs. Biological Reviews 2011, 86, 311-339.

38. Moger, J.; Johnston, B. D.; Tyler, C. R., Imaging metal oxide nanoparticles in biological structures with CARS microscopy. Opt. Express 2008, 16, (5), 3408-3419.

39. Garrett, N. L.; Lalatsa, A.; Begley, D.; Mihoreanu, L.; Uchegbu, I. F.; Schätzlein, A. G.; Moger, J., Label-free imaging of polymeric nanomedicines using coherent anti-stokes Raman scattering microscopy. Journal of Raman Spectroscopy 2012, 43, (5), 681-688.

40. Garrett, N. L.; Lalatsa, A.; Uchegbu, I.; Schätzlein, A.; Moger, J., Exploring uptake mechanisms of oral nanomedicines using multimodal nonlinear optical microscopy. Journal of Biophotonics 2012, 5, (5-6), 458-468. 
41. Tarran, G. A.; Heywood, J. L.; Zubkov, M. V., Latitudinal changes in the standing stocks of nano- and picoeukaryotic phytoplankton in the Atlantic Ocean. Deep-Sea Research I/ 2006, 15161529.

42. Frost, B. W., Effect of size and concentration of food particles on the feeding behaviour of the marine planktoinic copepod Calanus pacificus. Limnology and Oceanography 1972, 17, 805-815. 43. Roberts, E. C.; Wootton, E. C.; Davidson, K.; Jeong, H. J.; Lowe, C. D.; Montagnes, D. J. S., Feeding in the dinoflagellate Oxyrrhis marina: linking behaviour with mechanisms. 2011, 33, (4), 603614.

44. Huntley, M. E.; Barthel, K. G.; Star, J. L., Particle rejection by Calanus pacificus: discrimination between similarly sized particles. Marine Biology 1983, 74, 151-160.

45. Fernandez, F., Particle selection in the nauplius of Calanus pacificus. Journal of Plankton Research 1979, 1, (4), 313-327.

46. Hammer, A.; Grüttner, C.; Schumann, R., The Effect of Electrostatic Charge of Food Particles on Capture Efficiency by Oxyrrhis marina Dujardin (Dinoflagellate). Protist 1999, 150, (4), 375-382.

47. Christaki, U.; Dolan, J. R.; Pelegri, S.; Rassoulzadegan, F., Consumption of Picoplankton-Size Particles by Marine Ciliates: Effects of Physiological State of the Ciliate and Particle Quality. Limnology and Oceanography 1998, 43, (3), 458-464.

48. Juchelka, C. M.; Snell, T. W., Rapid toxicity assessment using ingestion rate of cladocerans and ciliates. Arch. Environ. Contam. Toxicol. 1995, 28, (4), 508-512.

49. Chan, W. Y.; Witting, J., The impact of microplastics on salp feeding in the tropical Pacific. The ANU Undergraduate Research Journal 2012, 4.

50. Powell, M. D.; Berry, A., Ingestion and regurgitation of living and inert materials by the estuarine copepod Eurytemora affinis (Poppe) and the influence of salinity. Estuarine, Coastal and Shelf Science 1990, 31, (6), 763-773.

51. Lam, R. K.; Frost, B. W., Model of Copepod Filtering Response to Changes in Size and Concentration of Food. Limnology and Oceanography 1976, 21, (4), 490-500.

52. Tiselius, P., Behavior of Acartia Tonsa in Patchy Food Environments. Limnology and Oceanography 1992, 37, (8), 1640-1651.

53. Paffenhöfer, G.; Van Sant, K. B., The feeding response of a marine planktonic copepod to quantity and quality of particles. Mar Ecol Prog Ser 1985, 27, 55-65.

54. Donaghay, P.; Small, L., Food selection capabilities of the estuarine copepod Acartia clausi. Marine Biology 1979, 52, (2), 137-146.

55. Hansen, B.; Hansen, P. J.; Nielsen, T. G., Effects of large nongrazable particles on clearance and swimming behaviour of zooplankton. Journal of Experimental Marine Biology and Ecology 1991, 152, (2), 257-269.

56. Teuten, E. L.; Rowland, S. J.; Galloway, T. S.; Thompson, R. C., Potential for Plastics to Transport Hydrophobic Contaminants. Environmental Science \& Technology 2007, 41, (22), 77597764.

57. Betts, K., Why small plastic particles may pose a big problem in the oceans. Environmental Science \& Technology 2008, 42, (24), 8995-8995.

58. Lithner, D.; Larsson, Å.; Dave, G., Environmental and health hazard ranking and assessment of plastic polymers based on chemical composition. Science of The Total Environment 2011, 409, (18), 3309-3324.

59. Oehlmann, J. r.; Schulte-Oehlmann, U.; Kloas, W.; Jagnytsch, O.; Lutz, I.; Kusk, K. O.; Wollenberger, L.; Santos, E. M.; Paull, G. C.; Van Look, K. J. W.; Tyler, C. R., A critical analysis of the biological impacts of plasticizers on wildlife. Philosophical Transactions of the Royal Society B: Biological Sciences 2009, 364, (1526), 2047-2062.

60. Urrère, M. A.; Knauer, G. A., Zooplankton fecal pellet fluxes and vertical transport of particulate organic material in the pelagic environment. Journal of Plankton Research 1981, 3, (3), 369-387. 
584 61. DeMott, W. R.; Watson, M. D., Remote detection of algae by copepods: responses to algal 585 size, odors and motility. Journal of Plankton Research 1991, 13, (6), 1203-1222.

586 62. Dagg, M., Some effects of patchy food environments on copepods. Limnology and 587 Oceanography 1977, 99-107.

588 63. Andrady, A. L., Microplastics in the marine environment. Marine Pollution Bulletin 2011, 62, 589 (8), 1596-1605.

590 64. Doyle, M. J.; Watson, W.; Bowlin, N. M.; Sheavly, S. B., Plastic particles in coastal pelagic 591 ecosystems of the Northeast Pacific ocean. Marine Environmental Research 2011, 71, (1), 41-52. 